\title{
Lattice Benchmarking of Deterministic, Monte Carlo and Hybrid Monte Carlo Reactor Physics Codes For the Soluble-Boron-Free SMR Cores
}

\author{
Syed Bahauddin Alam ${ }^{\mathrm{a}, *}$, Dinesh Kumar ${ }^{\mathrm{c}}$, Bader Almutairi ${ }^{\mathrm{d}}$, Tuhfatur Ridwan ${ }^{\mathrm{a}}$, Cameron \\ Goodwin $^{\mathrm{b}}$, Geoffrey T. Parks ${ }^{\mathrm{a}}$ \\ ${ }^{a}$ Department of Engineering, University of Cambridge, Cambridge, CB2 1PZ, United Kingdom \\ ${ }^{b}$ Rhode Island Nuclear Science Centre, 16 Reactor Rd, Narragansett, RI 02882, USA \\ ${ }^{c}$ Department of Physics and Astronomy, Uppsala University, Sweden \\ ${ }^{d}$ Department of Nuclear Engineering, Missouri SET, USA
}

\begin{abstract}
Since the use of deterministic transport code WIMS can significantly reduce the computational time compared to the Monte Carlo (MC) code Serpent and hybrid MC code MONK, one of the major objectives of this study is to observe whether deterministic code WIMS can provide accuracy in reactor physics calculations while comparing Serpent and MONK. Therefore, numerical benchmark calculations for a soluble-boron-free (SBF) small modular reactor (SMR) assembly have been performed using the WIMS, Serpent and MONK. Although computationally different in nature, these codes can solve the neutronic transport equations and calculate the required neutronic parameters. A comparison in neutronic parameters between the three codes has been carried out using two types of candidate fuels: $15 \%{ }^{235} \mathrm{U}$ enriched homogeneously mixed all- $\mathrm{UO}_{2}$ fuel and $18 \%{ }^{235} \mathrm{U}$ enriched micro-heterogeneous $\mathrm{ThO}_{2}-\mathrm{UO}_{2}$ duplex fuel in a $2 \mathrm{D}$ fuel assembly model using a $13 \times 13$ arrangement. The eigenvalue/reactivity $\left(k_{\infty}\right)$ and $2 \mathrm{D}$ assembly pin power distribution at different burnup states in the assembly depletion are compared using three candidate nuclear data files: ENDF/BVII, JEF2.2 and JEF3.1. A good agreement in $k_{\infty}$ values was observed among the codes for both the candidate fuels. The differences in $k_{\infty}$ between the codes are $\sim 200 \mathrm{pcm}$ when cross-sections based on the same nuclear data file are used. A higher difference (up to 450 $\mathrm{pcm}$ ) in the $k_{\infty}$ values is observed among the codes using cross-sections based on different data files. Finally, it can be concluded from this study that the good agreement in the results between the codes found provides enhanced confidence that modeling of SBF, SMR propulsion core systems with micro-heterogeneous duplex fuel can be performed reliably using deterministic neutronics code WIMS, offering the advantage of less expensive computation than that of the MC Serpent and hybrid MC MONK codes.
\end{abstract}

\footnotetext{
* Corresponding author

Email address: syed.nuclear@cantab.net (Syed Bahauddin Alam)
} 


\section{Introduction}

Small modular reactors (SMR) have become a topic of interest in Generation IV (Gen IV) advanced reactor technology in order to avoid the costly initial capital investment required for typical land-based nuclear power plants (Vujić et al., 2012a). Advanced SMRs have the capability to provide affordable nuclear power options while ensuring safe and clean energy. According to the definition and published reports by International Atomic Energy Agency (IAEA), the power output of SMRs are up to 300 MWe (IAEA, 2014, Cooper, 2014, Vujić et al., 2012b, Ramana et al., 2013, Lokhov et al., 2016). This advanced SMR technology has the potential to offer not only simpler but also safer modular design in the nuclear power generation application areas while being cheaper and easily manufacturable. (Hirdaris et al., 2014a,b). The fundamental research and policy objectives on advanced SMR designs aim to provide enhanced safety, non-proliferation and economics. Currently, advanced and innovative designs with advanced safety features are implemented in advanced SMRs (Hirdaris et al., 2014a). According to Clegg and Shanawany (Clegg and Shanawany, 2012), SMRs can be divided into three groups:

- Type I SMRs are early deployment light water reactor (LWR) designs based on PWR technology. They use light water as moderator and coolant.

- Type II SMRs are smaller in size than that of Type I and being considered for medium-to-long-term deployment while following the design principle of fast reactors (Hirdaris et al., 2014a,b). Typically, the Type II SMRs use liquid metals as coolants and require higher enrichment $(>20 \%)$ to achieve a long core lifetime than comparable thermal reactors.

- Type III SMRs are advanced reactor concept with very high temperature and this type is termed as Advanced High-Temperature Reactor (AHTR). Type III AHTR can be cooled by either liquid salt or liquid metal. Since this is a new reactor technology with having less experience, this Type III SMRs are expected to face difficulty and more challenges in licensing than other two counterparts (Hirdaris et al., 2014a,b).

The US Department of Energy (DOE) has performed studies regarding the prospect of SMRs and concluded that SMRs have the capability and excellent promise to contribute significantly to the energy security (Zohuri and McDaniel, 2019, IAEA, 2014). Strong support is provided by DOE to the development of LWR-based Type I SMRs, which are currently under the processing of licensing by the US Nuclear Regulatory Commission. It is thus expected that Type I SMRs can be deployed by the next 20 years (Zohuri and McDaniel, 2019, IAEA, 2014). In summary, with a proven record of power generation and safe operation, the LWR-based PWR (Type I SMR) is the most common reactor in today's world. It is thus expected that LWR technology-based Type I SMR cores will be much easier to license by Nuclear Regulatory Commission and, therefore, near-term deployment of this type of SMR is indeed possible (Pramuditya and Takahashi, 2013).

The study of SMR core design for the specific application of civil nuclear marine propulsion has been performed as a part of the Ph.D. research at the University of Cambridge (Alam, 
2018) and builds on the previous studies related to the civil marine SMR core design studies conducted at Cambridge University (Fan, 2012, Zhang, 2013, Sun, 2014, Otto, 2013). This Ph.D. project focused on designing a single-batch SMR core which has the feature of long core lifetime (at least 15 years) while utilizing low enriched uranium (below 20\% uranium enrichment). It did not employ soluble boron for reactivity control in order to avoid the complexity in core design. Since this study did not use soluble boron and used enrichment higher than the civil nuclear power plant (3-5\% uranium enrichment) to ensure long core lifetime, an attempt was made to investigate an alternative fuel platform which has the inherent characteristics of providing lower beginning-of-life (BOL) reactivity and through-life reactivity swing (Alam et al., 2019c,d).

In order to explore an alternative fuel platform, this $\mathrm{Ph}$.D. research started to investigate the feasibility of duplex fuel since it has not been employed before in the context of SBF and long-life SMR core (Zhao, 2001, MacDonald and Lee, 2004). Generally speaking, thorium fuel can be designed primarily by adopting three distinct strategies: homogeneous mixtures, heterogeneous geometries and micro-heterogeneous geometries. It has been observed that homogeneously mixed fuel can only demostrate superior performance in terms of achieving the desired discharge burnup, when enrichment is more than 20\% (Otto, 2013, Galperin et al., 2002). On the contrary, since the heterogeneous strategy consists of seed and blanket, it is required to replace the seed region with fresh fuel in the middle-of-life of the core (Todosow et al., 2005).

For the target application in the context of long-life and SBF core while utilizing low enriched uranium (LEU), homogeneous and heterogeneous strategies are not feasible options since our application is targeted for the single-batch operation plan (where replacement of seed is not possible) and enrichment cannot be exceeded more than $20 \%$ due to the proliferation concern. In this regard, our study evaluated the feasibility of thorium-based micro-heterogeneous duplex fuel for the target application since this fuel candidate has never been utilized for the SBF and long-life SMR core application (MacDonald and Lee, 2004). Most importantly, since this fuel is utilized in our proposed SMR lattice, it is important to ensure that the neutronic results obtained for this fuel are sufficiently accurate while considering the standard reactor physics codes. Therefore, lattice-level numerical benchmarking has been performed in this study for the duplex fuel. In order to provide enhanced confidence on the codes, the numerical benchmarking of the homogeneously mixed $\mathrm{UO}_{2}$ fuel has also been performed.

Until now all the SMR benchmarking studies have been performed for the uranium-based fuel and limited to the soluble-boron system. Therefore, it is a motivation to assess the 2D lattice benchmarking of SMR for a thorium-based duplex fuel in a SBF environment. The main objective of this benchmarking study is to assure that deterministic code can significantly reduce the computational time for the candidate fuels in the lattice-level calculation since deterministic code is computationally much cheaper than that of the Monte Carlo (MC) and hybrid MC codes. In addition, since our lattice calculations are performed for the high burnup application (0-100 GWd/tonne) (Alam et al., 2019c) using fine burnup steps (burnup step of $2 \mathrm{GWd}$ /tonne), MC and Hybrid MC codes will be extremely computationally expensive. Therefore, if it can be assured that the deterministic code can be used with accepted accuracy 
while comparing the results with the candidate $\mathrm{MC}$ and hybrid $\mathrm{MC}$ codes, the computational time can be significantly reduced for such high burnup applications. In order to obtain and ensure sufficient accuracy, numerical benchmark calculations for a SBF SMR assembly have been performed using three different types of transport codes: the deterministic transport code WIMS (Lindley et al., 2017, Newton et al., 2008), MC code Serpent (Leppänen, 2012, Leppänen and Isotalo, 2012) and hybrid MC code MONK (Hutton and Smith, 2001, Long et al., 2015).

All three candidate codes: WIMS, MONK and Serpent can solve the neutronic transport equations and can calculate the reactor physics parameters of interest. A comparison in neutronic parameters between the three codes has been carried out with a 2D fuel assembly model using a $13 \times 13$ arrangement. This study examines two types of candidate fuels: homogeneously mixed all- $\mathrm{UO}_{2}$ fuel and micro-heterogeneous $\mathrm{ThO}_{2}-\mathrm{UO}_{2}$ duplex fuel while employing $15 \%$ and $18 \%$ of initial uranium enrichment, respectively. The term "duplex" will be used throughout this paper for the "micro-heterogeneous $\mathrm{ThO}_{2}-\mathrm{UO}_{2}$ duplex fuel".

The main motivations behind this numerical benchmarking study are:

1. Until now all the SMR benchmarking studies have performed only for the uraniumbased fuel with the soluble-boron system. In addition, duplex fuel has not been assessed in SBF and SMR environments. Therefore, it is important to observe whether deterministic WIMS code can be reliably used for both these candidate fuels in SBF and SMR environments.

2. Since the use of deterministic code WIMS can significantly reduce the computational time than that of the MC Serpent and hybrid MC MONK codes, this paper aims to observe whether deterministic transport code WIMS can provide accuracy in evaluating reactivity while comparing Serpent and MONK.

3. The goal of this study is not to perform detailed neutronic parameters for the lattice benchmarking. In the interest of brevity, the objective is just to ensure that WIMS reactivity values are in acceptable/excellent agreement with other candidate codes to justify the reliable use of WIMS while offering the advantage of less expensive computation than that of the MC Serpent and hybrid MC MONK codes.

In accordance with the objectives described above, this paper considers the following evaluation for both the candidate fuels:

- Eigenvalue ${ }^{1}\left(k_{\infty}\right)$ criticality calculations are performed using all the three candidate codes: WIMS, MONK and SERPENT.

- Data library discrepancies are performed for three nuclear data library files: ENDF/BVII, JEF2.2 and JEF3.1 for evaluating criticality values using WIMS and MONK. In order to avoid the redundancy, SERPENT results for the data library discrepancies are not provided.

\footnotetext{
${ }^{1}$ The terms 'eigenvalue', 'reactivity' and 'criticality' are used interchangeably throughout the study and referred as $k_{\infty}$.
} 
- 2D assembly pin power distribution at different burnup states in the assembly depletion are compared using three nuclear data files: ENDF/B-VII, JEF2.2 and JEF3.1 Assembly pin power was evaluated using WIMS only.

\section{Design and calculational methods}

\subsection{Calculation routes}

The study of SMR employs reactor physics codes WIMS, MONK and SERPENT. This study uses a $13 \times 13$ assembly design of a SMR core, as shown in Fig. 1. This SMR core has an average power density of $63 \mathrm{MW} / \mathrm{m}^{3}$ and average linear rating of $10 \mathrm{~kW} / \mathrm{m}$ (Alam et al., 2019c).

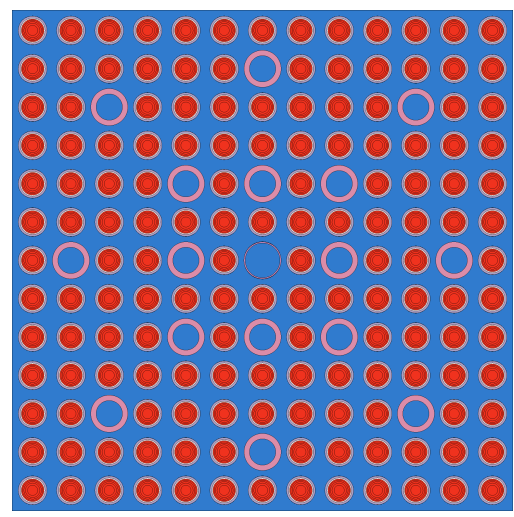

Fig. 1. $13 \times 13$ geometry layout of the $2 \mathrm{D}$ subassembly.

The 2D assembly/lattice design analysis for our proposed SMR core relied on WIMS10 (Winfrith Improved Multigroup Scheme) lattice physics code. WIMS-10 generates an assembly-specific cross-section library and use this order to compute a numerical solution for the neutron transport equation. The calculations are performed for a simplified twodimensional geometry with reflective boundary conditions, ie. an infinite array of infinitely tall assemblies. The output specifies the neutron flux, the cross-sections of various isotopes, and the pin-by-pin power peaking factors. The calculational route used in the subassembly study is handled through a sequence of separate modules, that were executed over a lifetime of discrete burnup intervals. WIMS completes a 172-group solution to the neutron transport equation in a smeared geometry for each burnup step. Using a few-group calculation ( smaller number of energy groups) in a precise geometry, it then refines this solution. The WIMS calculation route is as follows (Zainuddin, 2015, Alam, 2018, Newton, 2009b):

1. HEAD generates an interface containing microscopic cross-sections for all nuclides in the problem, at the required temperatures and performs an equivalence treatment of resonance shielding section.

2. PRES/CACTUS/RES: PRES sets up a new interface containing subgroup cross-sections that have been obtained by fitting to the library resonance integrals. CACTUS performs the subgroup flux solution by the method of characteristics (MoC). Subgroup fluxes 
are evaluated by RES module, where fluxes are a set of weights for each WIMS library resonance group, and an appropriately-weighted broad group resonance cross-section.

3. PERSEUS/PIP: PERSEUS module solves collision probability equations for the specified problem. PIP generates a flux solution and calculates an estimated $k_{\infty}$ and fluxes from the PERSEUS collision probabilities for each of the problem regions and hence for each material in the problem.

4. COND generates cross sections in 6 groups. Uses an "energy" vector to define condensation in 6 groups.

5. DIFF creates n-number of differential materials on cycle 1.

6. CACTUS solves the multigroup neutron transport equations via the method of characteristics. Identical to that used in the subgroup treatment. Now it is calculating 6 -group fluxes and $k_{\infty}$ for the symmetric quarter problem.

7. CRITIC/SMEAR: CRITIC reads a nominal radial buckling and a radial perturbation, and searches for the radial buckling that gives k-effective of 1.0. i.e. adjust fluxes for critical leakage. SMEAR uses the critical spectrum output by CRITIC to generate a new interface with the data, smeared into a single material.

8. LED prepares data for the whole-core code.

9. BURNUP performs a material burnup calculation by integrating the depletion equations within the material regions of a lattice cell, with or without burnable poison. If with $\mathrm{BP}$, then poison flux shape will be recalculated so that the reaction rates through the pin can be readjusted, i.e. it repeatedly adjusts the flux depression in the poison pin as the poison burns out. Also uses the differential option in BURNUP to point to differential versions of fuel material in the alpha and BP treatments. The output interface contains depleted number densities, which are read by HEAD at the start of the next cycle.

The MONK (Newton, 2009a) is used in this paper to perform a Monte Carlo solution within a WIMS calculation route. MONK uses the multigroup cross-section prepared by WIMS-10. This study uses a module named MONK for considering resonance treatment by NOVICE method. By using the NOVICE method, similar to WIMS calculation, HEAD prepares an interface for MONK module. WIMS then can continue its requested calculations as soon as MONK module is completed.

MC code Serpent is also used for lattice benchmarking, which is a continuous energy code. The neutron transport routine in Serpent combines both the Woodcock delta-tracking method (Leppänen, 2010) and surface-to-surface ray-tracing (Leppänen and Pusa, 2009). The Woodcock method is well-suited for the LWR-based lattice physics applications as it is an efficient alternative to surface tracking (Leppänen, 2010). Hence, Serpent is chosen for this work not only because of its flexibility but also for the efficiency that it offers by combining two different tracking methods. Chebyshev Rational Approximation Method (Leppänen et al., 2014) is employed in Serpent depletion calculations (Fratoni and Terrani, 2017). 


\subsection{Fissile loading design}

This study focuses on homogeneously mixed $\mathrm{UO}_{2}$ fuel and duplex fuel in a $13 \times 13$ assembly, as shown in Fig. 1. The micro-heterogeneous configuration of the duplex fuel (Fig. 2) is described in detail in our previous studies (Alam et al., 2019a, 2018c,d).

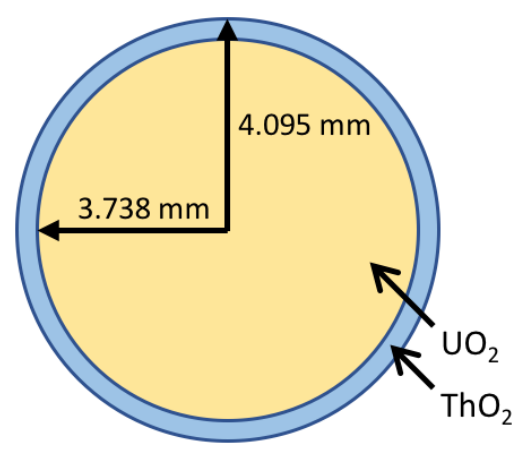

Fig. 2. Micro-heterogeneous duplex fuel with $\mathrm{ThO}_{2}-\mathrm{UO}_{2}$ configuration.

From the perspective of the fuel irradiation tolerance, $100 \mathrm{GWd} /$ tonne is assumed as the limit of highest discharge burnup considering 7.5\% neutron leakage in WIMS model. We have considered higher leakage in our SMR core design than the standard PWR $(\sim 4 \%$ neutron leakage) since our proposed core is smaller in size and consequently is more prone to leakage. The rationality of considering $7.5 \%$ leakage is discussed in detail in our previous papers (Alam et al., 2019c, Alam, 2018, Alam et al., 2019b).

The assembly burnup curves shown in Figs. 3a and 3b are used to estimate the discharge burnup using a sensitivity analysis. We can observe that the desired discharge burnup of $\sim 95$ $\mathrm{GWd} /$ tonne is attained at the $k_{\infty}$ of 1.075 if $15 \%$ and $18 \%$ of initial uranium enrichment is used.

Therefore, our SMR subassembly design uses $15 \%$ and $18 \%{ }^{235} \mathrm{U}$ enriched for the candidate fuels: $\mathrm{UO}_{2}$ and duplex in a $13 \times 13$ assembly. Table 1 shows the design parameters for the $2 \mathrm{D}$ lattice of the proposed SBF, SMR core (Alam et al., 2018a,b,c,d, 2016a,b).

\section{Criticality benchmark calculations}

The eigenvalue $\left(k_{\infty}\right)$ at different burnup states in the assembly depletion with their reference $^{2}{ }^{235} \mathrm{U}$ contents are compared using several nuclear data files: JEF-2.2, JEF-3.1 and ENDF/B-VII. Fig. 4 shows $k_{\infty}$ versus burnup for candidate fuels: all- $\mathrm{UO}_{2}$ and duplex fuels in a $13 \times 13$ arrangement calculated with WIMS, MONK and Serpent codes using the data libraries. It is important noting that " $U$ " and " $\mathrm{D}$ " are short-hand labels for all- $\mathrm{UO}_{2}$ and duplex fuels, respectively in the figures. In addition, "g" is the short-hand label for the number of energy groups.

${ }^{2235} \mathrm{U}$ content: $15 \%$ and $18 \%$ for for $\mathrm{UO}_{2}$ duplex fuels, respectively. 


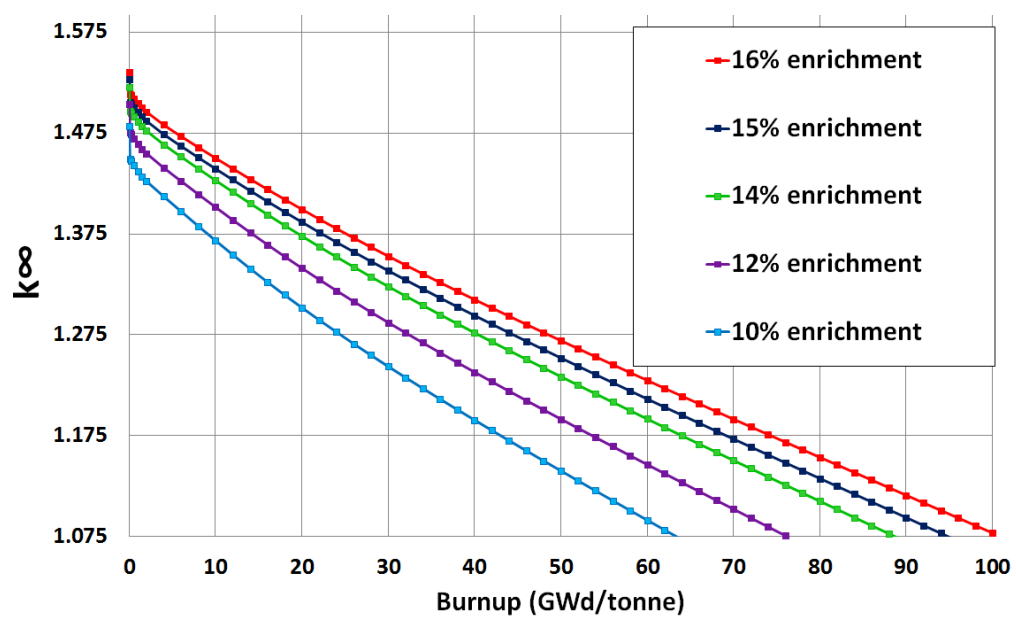

(a)

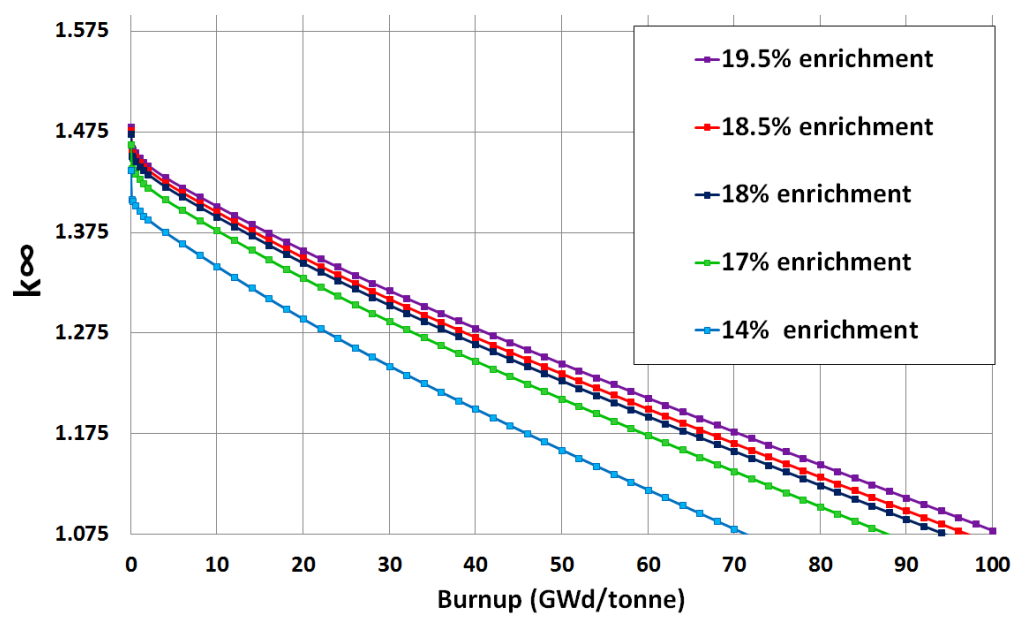

(b)

Fig. 3. Parametric enrichment calculations for candidate fuels for determining fissile loading: (a) $\mathrm{UO}_{2}$; (b) Duplex. 


\begin{tabular}{|l|c|}
\hline Design Parameters & Values \\
\hline Thermal power (MWth) & 333 \\
Thermal efficiency (\%) & 30 \\
Desired electrical power (MWe) & 100 \\
Availability & 1.00 \\
Maximum discharge burnup (GWd/tonne) & 100 \\
Minimum core lifetime (years) & 15 \\
Assembly array & $13 \times 13$ \\
Control rods per assembly & 16 \\
Centre-to-centre pitch (cm) & 1.265 \\
Pellet thickness (mm) & 8.19 \\
Cladding + gap thickness (mm) & 0.66 \\
Total rod diameter (mm) & 9.5 \\
Fuel height (cm) & 179 \\
Core diameter (cm) & 197 \\
Pitch/diameter (P/D) ratio & 1.33 \\
Side length of an assembly (m) & 0.1645 \\
Area of an Assembly (cm $\left.{ }^{2}\right)$ & 300 \\
H/HM ratio & 3.99 \\
Soluble boron concentration (ppm) & 0 \\
\hline
\end{tabular}

Table 1. Design parameters of proposed SMR core. 


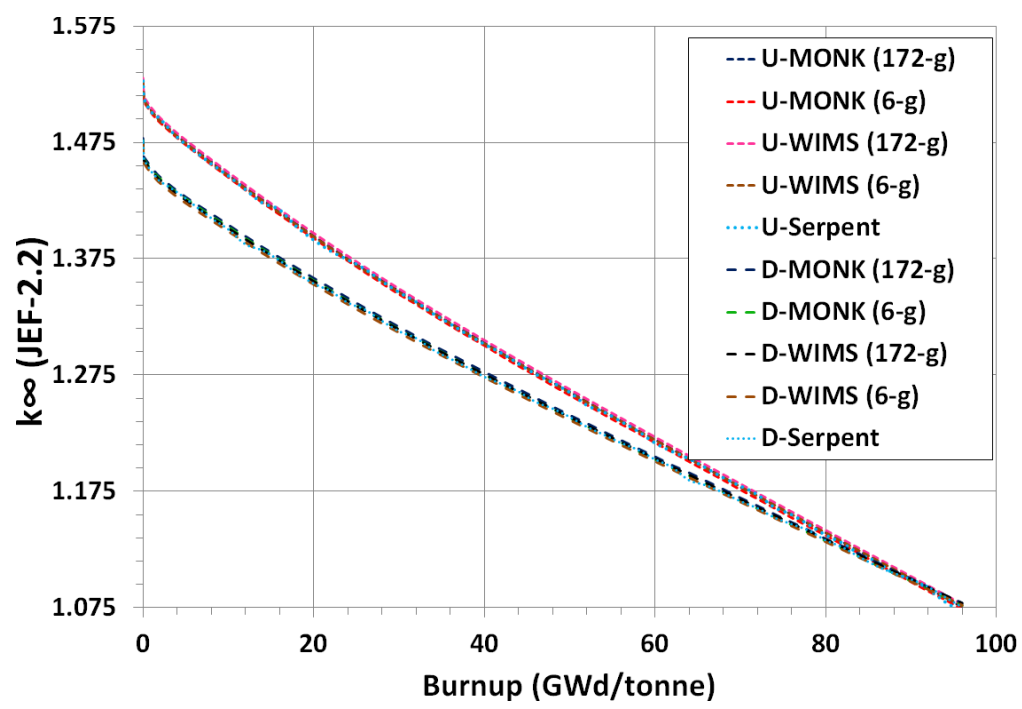

(a)

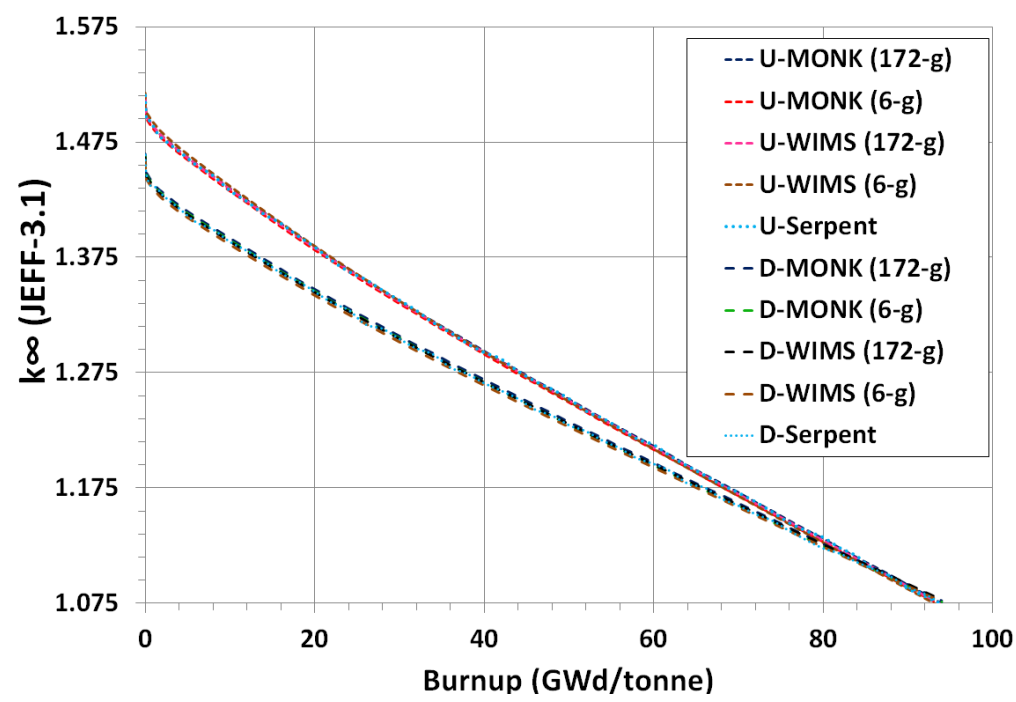

(b)

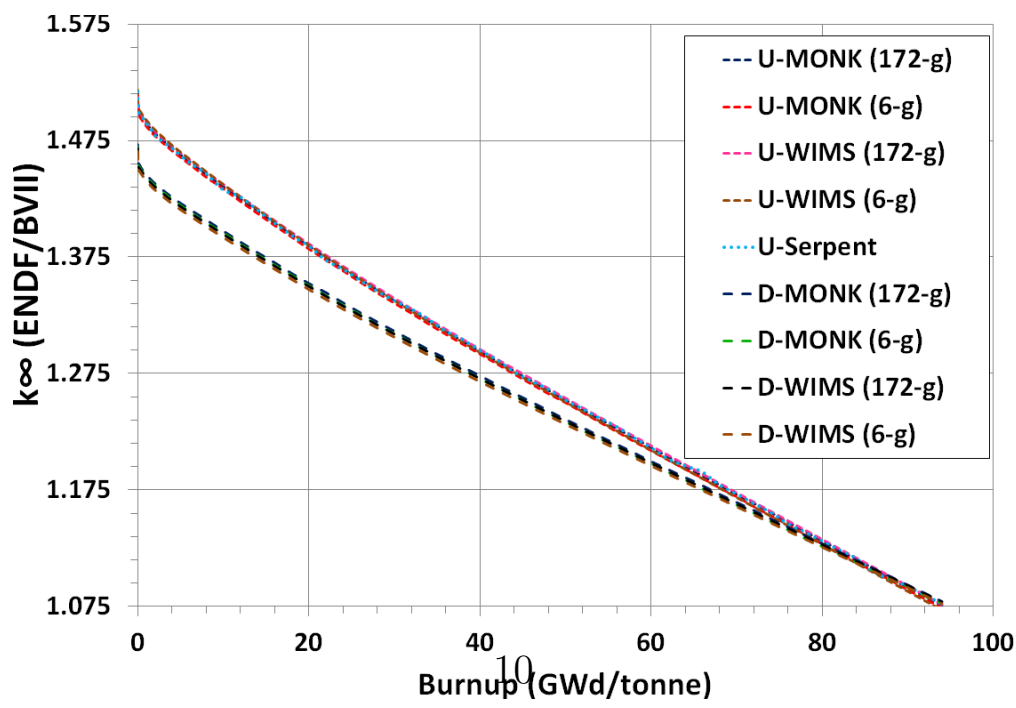

(c)

Fig. 4. $k_{\infty}$ over burnup for $\mathrm{UO}_{2}$ and duplex fuels calculated with WIMS, MONK and Serpent ("U", "D" and "g" are the short-hand labels for $\mathrm{UO}_{2}$ and duplex and number of energy groups, respectively): (a) JEF-2.2 libraries; (b) JEFF-3.1 libraries; (c) ENDF/B-VII libraries. 


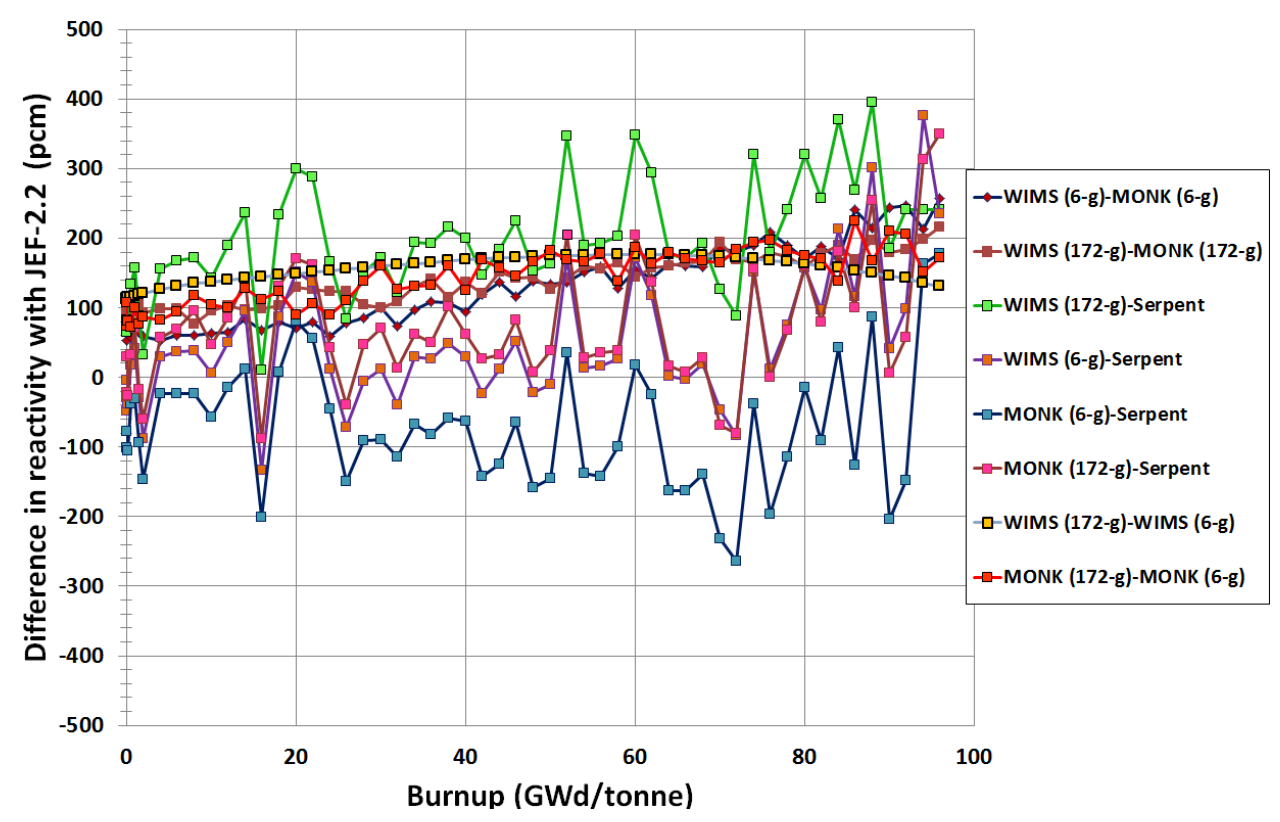

(a)

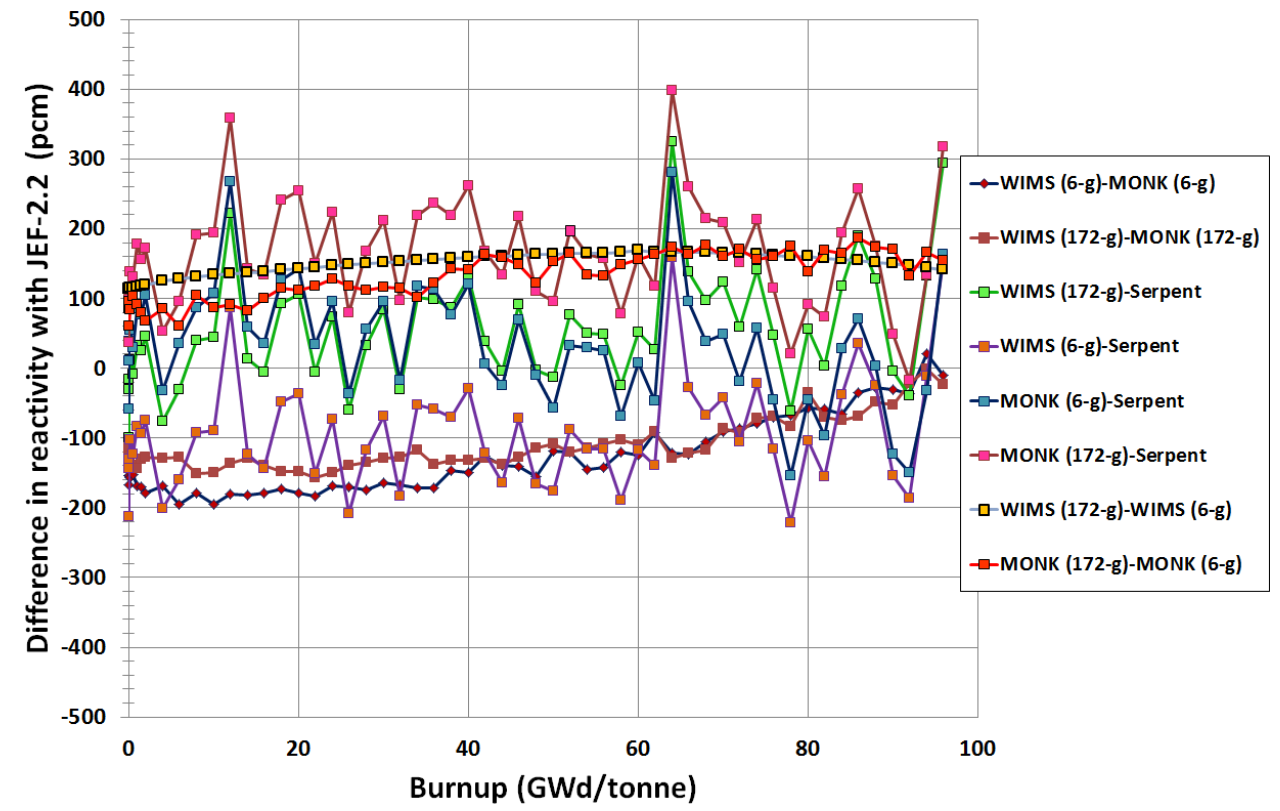

(b)

Fig. 5. Reactivity comparison (pcm) between the candidate codes using JEF-2.2 libraries using candidate fuels ( "g" is the short-hand label for the number of energy groups): (a) all- $\mathrm{UO}_{2}$; (b) Duplex. 


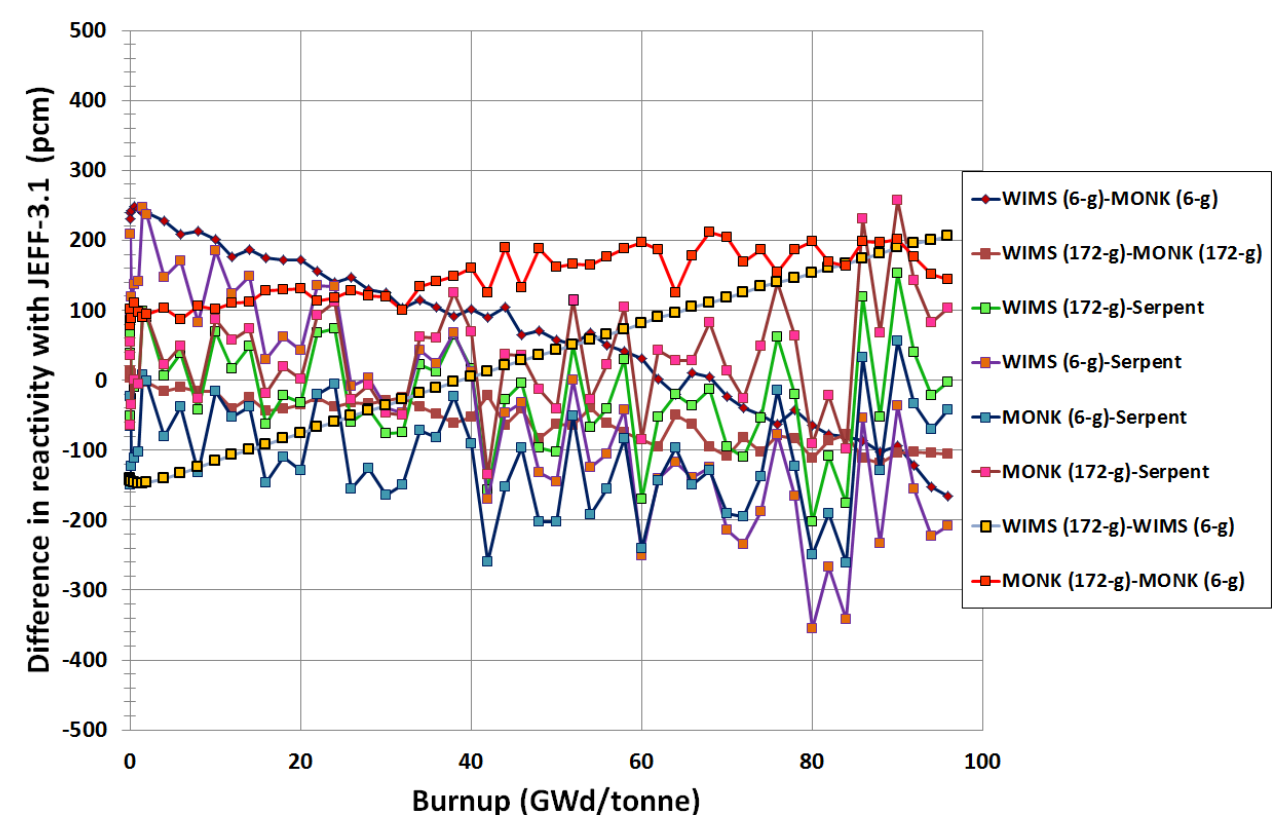

(a)

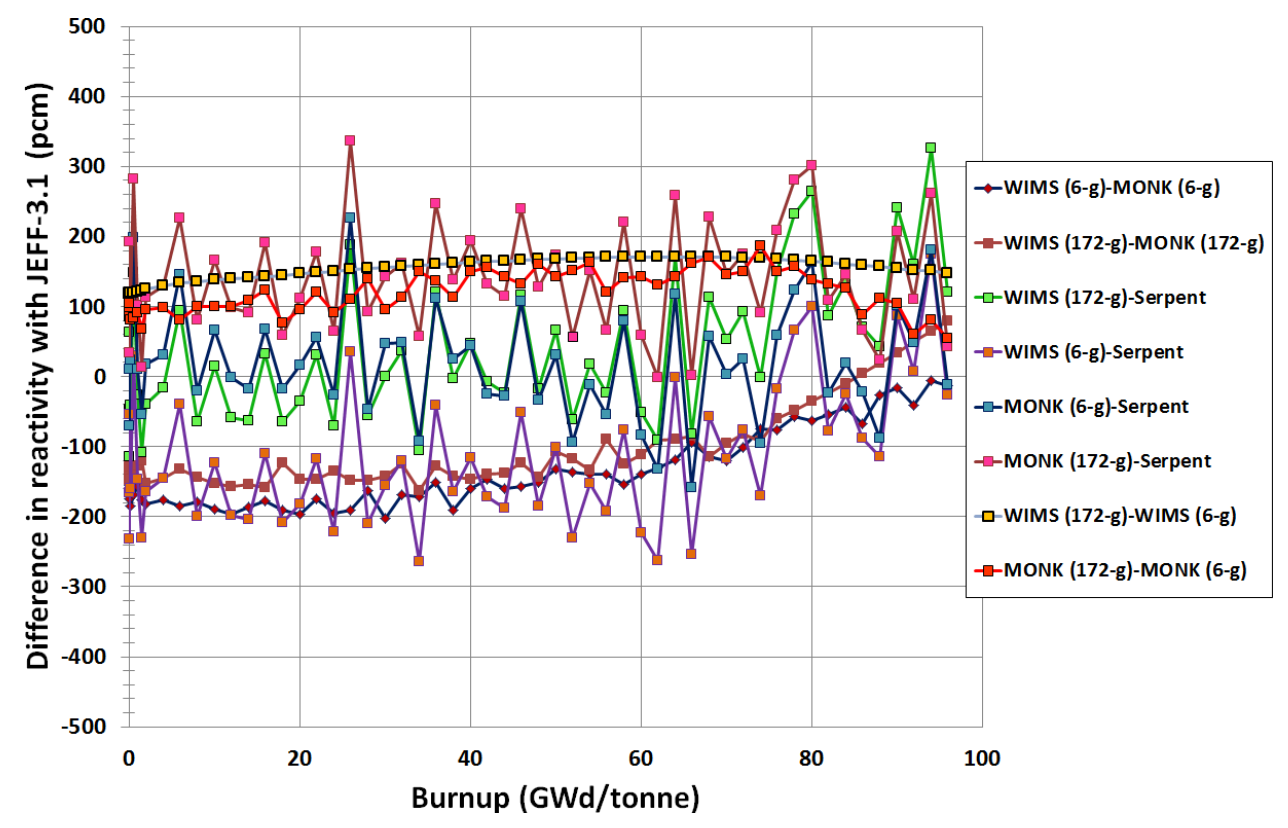

(b)

Fig. 6. Reactivity comparison ( $\mathrm{pcm}$ ) between the candidate codes using JEFF-3.1 libraries using candidate fuels ( "g" is the short-hand label for the number of energy groups): (a) all- $\mathrm{UO}_{2}$; (b) Duplex. 


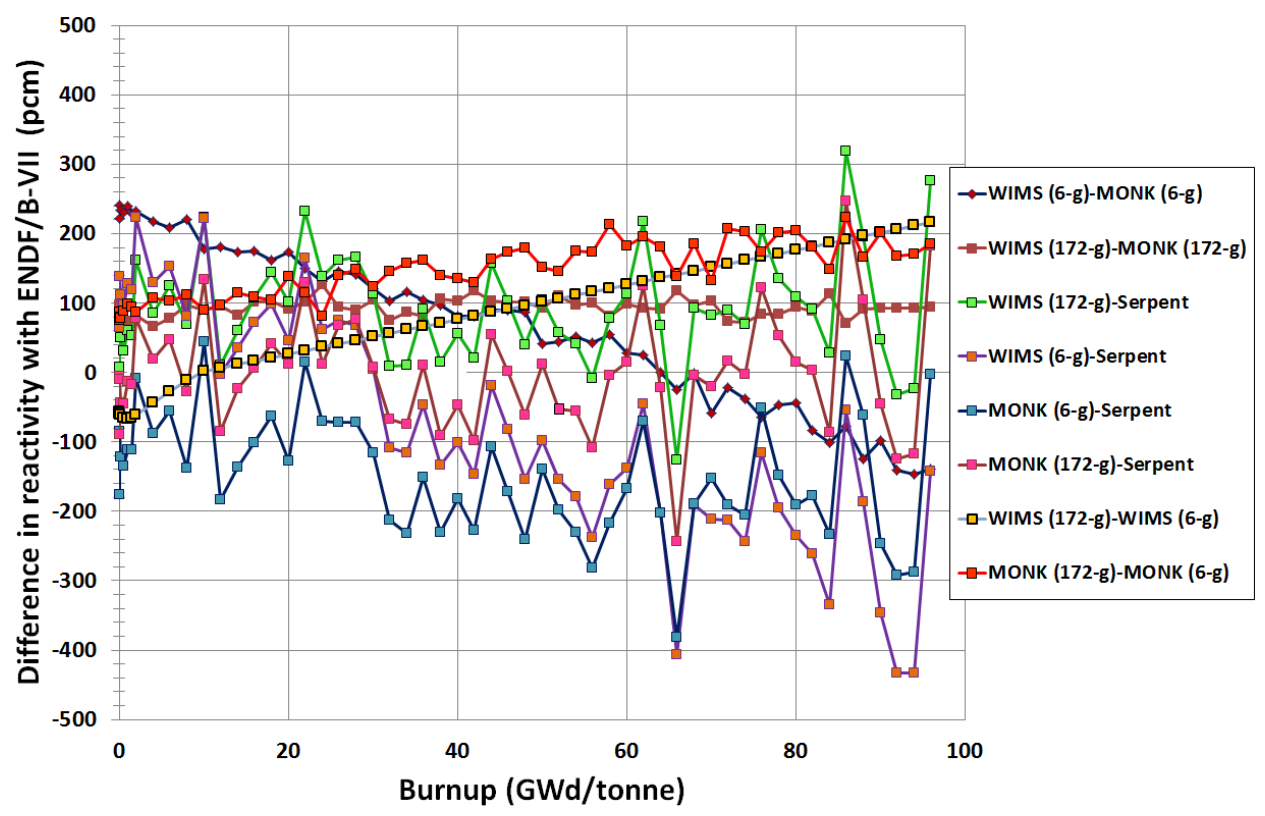

(a)

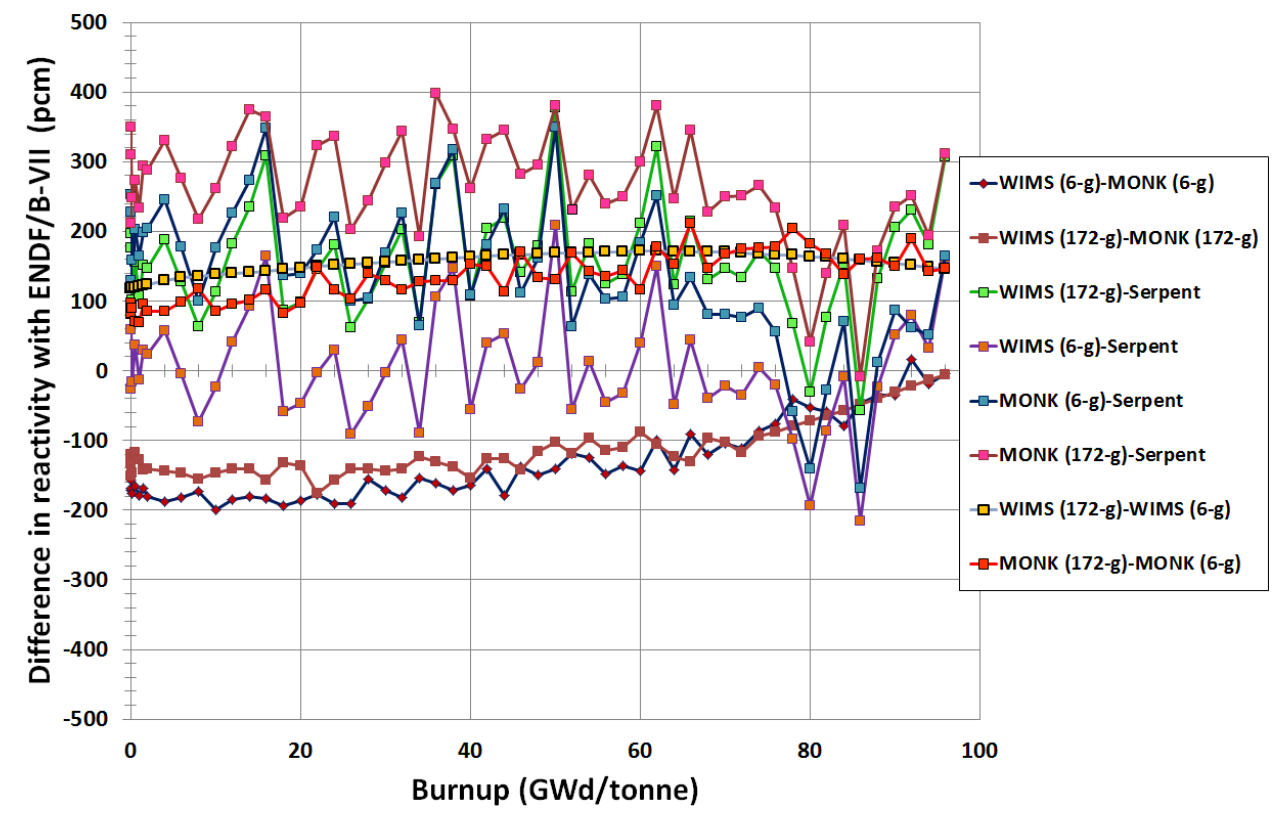

(b)

Fig. 7. Reactivity comparison ( $\mathrm{pcm}$ ) between the candidate codes using ENDF/B-VII libraries using candidate fuels ( "g" is the short-hand label for the number of energy groups): (a) all- $\mathrm{UO}_{2}$; (b) Duplex. 


\subsection{WIMS \& $M O N K$}

The variations of $k_{\infty}$ over burnup calculated with WIMS and MONK are shown in Figs. 5, 6 and 7 . The findings for the candidate fuels are:

- WIMS demonstrates a very good agreement with MONK with a maximum difference of $\sim 150-200 \mathrm{pcm}, \sim 100-150 \mathrm{pcm}$ and $\sim 120-170 \mathrm{pcm}$ using JEF2.2, JEF3.1 and ENDF/B-VII libraries, respectively with the 172 energy group.

- The condensed 6 energy group method introduces some additional errors between the codes. This results in the maximum differences of $\sim 200-250 \mathrm{pcm}$ are observed using these three data libraries.

\subsection{WIMS \& Serpent}

The variations of $k_{\infty}$ over burnup calculated with WIMS and Serpent are shown in Figs. 5, 6 and 7. It has been observed that:

- Slightly higher maximum differences are observed when comparing the results obtained from the WIMS and Serpent. The maximum differences of $\sim 300-400 \mathrm{pcm}, \sim 200-300$ pcm and $\sim 250-300$ pcm are observed using JEF2.2, JEF3.1 and ENDF/B-VII libraries, respectively with the 172 energy group.

- Data libraries with the condensed energy group do not introduce additional errors between these deterministic and MC codes, unlike ENDF/B-VII libraries. As a result, the maximum differences observed are $\sim 200-350 \mathrm{pcm}$ (errors are reduced with respect to 172 energy group), $\sim 200-300 \mathrm{pcm}$ (similar to 172 energy group) and $\sim 350-400$ pcm (errors are increased with respect to 172 energy group) using JEF2.2, JEF3.1 and ENDF/B-VII libraries, respectively.

\subsection{MONK \& Serpent}

The variations of $k_{\infty}$ over burnup calculated with MONK and Serpent are shown in Figs. 5, 6 and 7. The findings for the candidate fuels are:

- Due to the computational nature of the codes, it is expected that these codes will show similar differences to those observed between WIMS and Serpent, and this is reflected in the results.

- The maximum differences of $\sim 300-450 \mathrm{pcm}, \sim 250-350 \mathrm{pcm}$ and $\sim 250-400 \mathrm{pcm}$ are observed using JEF2.2, JEF3.1 and ENDF/B-VII libraries respectively, with the 172 energy group.

- Data libraries with the condensed energy group do not introduce additional errors between these deterministic and MC codes, unlike ENDF/B- VII libraries. As a result, the maximum differences observed were $\sim 250-280 \mathrm{pcm}$ (errors are reduced with respect to 172 energy group), $\sim 200-250 \mathrm{pcm}$ (errors are reduced with respect to 172-energy group) and $\sim 350-400 \mathrm{pcm}$ (errors are increased with respect to 172-energy group) using JEF2.2, JEF3.1 and ENDF/B-VII libraries, respectively. 


\subsection{Effect of energy group condensation in WIMS and MONK}

We have also observed whether WIMS and MONK incur any additional errors by condensing the energy groups from 172 to 6 energy group for the candidate data libraries. Figs. 5, 6 and 7 again show that

- WIMS exhibits the maximum differences of $\sim 169-176 \mathrm{pcm} ; \sim 171-200 \mathrm{pcm}$; and 171-216 pcm using JEF2.2, JEF3.1 and ENDF/B-VII libraries, respectively.

- MONK shows greater (in magnitude) maximum errors compared to that of WIMS as a result of condensing the energy groups. MONK exhibits the maximum differences of $\sim 18-225 \mathrm{pcm} ; \sim 187-211 \mathrm{pcm}$ and $\sim 211-223 \mathrm{pcm}$ using JEF2.2, JEF3.1 and ENDF/BVII libraries, respectively.

- The duplex fuel shows reduced error compared to the $\mathrm{UO}_{2}$ fuel for MONK and WIMS codes for all the data libraries while using condensed energy group.

\subsection{Key findings on verification using WIMS, MONK \& Serpent}

- It has been observed from the reactivity $\left(k_{\infty}\right)$ calculations that, fuel candidates exhibit an excellent agreement between WIMS and MONK for the candidate data libraries: JEFF-3.1, JEF-2.2, and ENDF/B-VII.

- Higher differences are observed in $k_{\infty}$ over burnup while comparing the results between Serpent and ANSWERS codes (WIMS and MONK).

- Most importantly, average differences (over burnup) in $k_{\infty}$ values between the codes are $\sim 100$ pcm, whereas individual burnup steps show the maximum differences.

- ANSWERS codes (WIMS and MONK) use COND module for the energy group condensation from 172 to 6 groups. Due to the energy group condensation in the ANSWER codes for both the candidate fuel lattices, an additional difference of $\sim 80-100$ pcm is observed.

- The main reasons behind the discrepancies in $k_{\infty}$ (over burnup) between the codes are due to the nature of the codes. Serpent is a monte Carlo code (combining both Woodcock delta-tracking and surface-to-surface ray-tracing methods) which uses continuous energy group (no energy condensation is used). On the contrary, WIMS is a deterministic code $(\mathrm{MoC})$ and the energy spectrum is restricted to 172 fine energy groups. In addition, hybrid monte Carlo code MONK uses multigroup cross-section prepared by deterministic WIMS.

- Due to the statistical nature of MC Serpent and hybrid MC MONK codes, the statistical errors are reported to be $10 \mathrm{pcm}$ for these codes.

In light of these considerations, it can be established that eigenvalue/reactivity discrepancies between the codes are within the acceptable range. 


\section{Data library discrepancies}

The data libraries that are available to use in our local repository are JEFF-3.1, JEF-2.2 and ENDF/B-VII. The same cases (as shown in section 3) are performed in WIMS and MONK for 172 group calculation with these three candidate data libraries to investigate and understand the discrepancies in the data library. In order to avoid the redundancy, SERPENT results for the data library discrepancies are not provided since SERPENT already shows an excellent agreement in reactivity values with WIMS and MONK. The differences in eigenvalues between the data libraries are evaluated with respect to JEF-2.2. This section focuses on observing the following:

- WIMS and MONK are used to observe the differences in eigenvalues $\left(k_{\infty}\right)$ for the candidate data libraries;

- WIMS is used to observe the differences (\%) in average assembly pin powers with respect to JEF-2.2.

\subsection{Eigenvalue $\left(k_{\infty}\right)$}

\subsubsection{JEF-2.2 vs. JEFF-3.1}

The difference in eigenvalue $\left(k_{\infty}\right)$ between JEF-2.2 vs. JEFF-3.1 can be seen in Figs. 8 and 9 for WIMS and MONK, respectively:

- For the duplex fuel, the average difference between JEF-2.2 and JEFF-3.1 is 600 pcm throughout the burnup in WIMS and MONK, although the maximum and minimum differences are $\sim 700 \mathrm{pcm}$ and $\sim 500 \mathrm{pcm}$, respectively.

- For the $\mathrm{UO}_{2}$ fuel, the average differences between JEF-2.2 and JEFF-3.1 are $~ 380$ pcm and $\sim 600 \mathrm{pcm}$ in WIMS and MONK, respectively. The $\mathrm{UO}_{2}$ fuel exhibits a maximum difference of $\sim 650 \mathrm{pcm}$ and $\sim 800 \mathrm{pcm}$ with WIMS and MONK, respectively.

- JEFF-3.1 consistently predicted slightly lower reactivity values than the JEF-2.2 in WIMS and MONK calculations.

\subsubsection{JEF-2.2 and ENDF/B-VII}

The difference in eigenvalue $\left(k_{\infty}\right)$ between JEF-2.2 and ENDF/B-VII can be seen in Figs. 8 and 9 for WIMS and MONK, respectively:

- For the duplex fuel, the average difference between JEF-2.2 and ENDF/B-VII is 350 pcm throughout the burnup in WIMS and MONK, although maximum and minimum differences are $\sim 550 \mathrm{pcm}$ and $\sim 300$ pcm, respectively.

- For the $\mathrm{UO}_{2}$ fuel, the average differences between JEF-2.2 and ENDF/B-VII are 340 pcm and $\sim 550 \mathrm{pcm}$ in WIMS and MONK, respectively.

- JEF-2.2 consistently predicted slightly higher reactivity values than that of the ENDF/BVII in both the WIMS and MONK codes. 


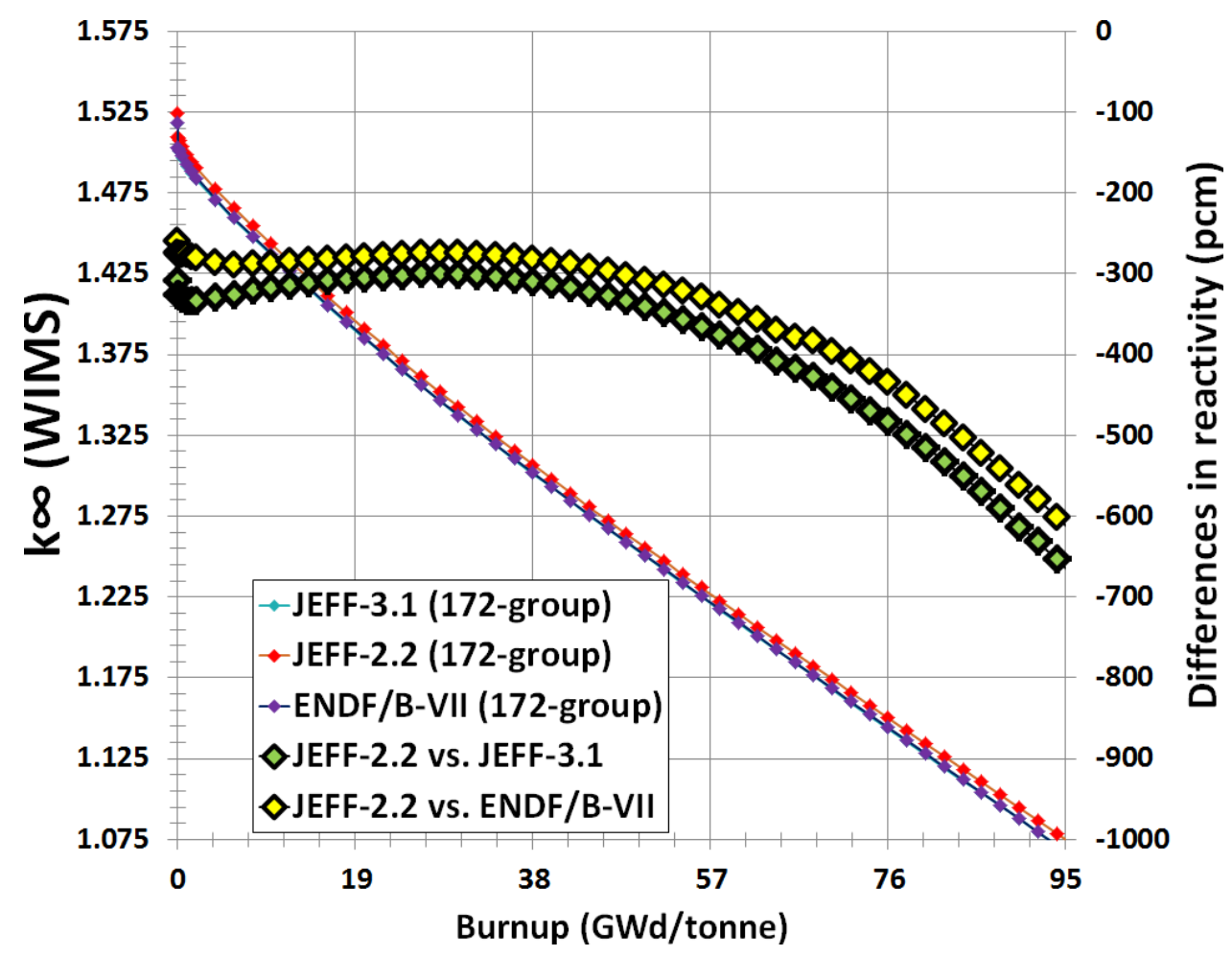

(a)

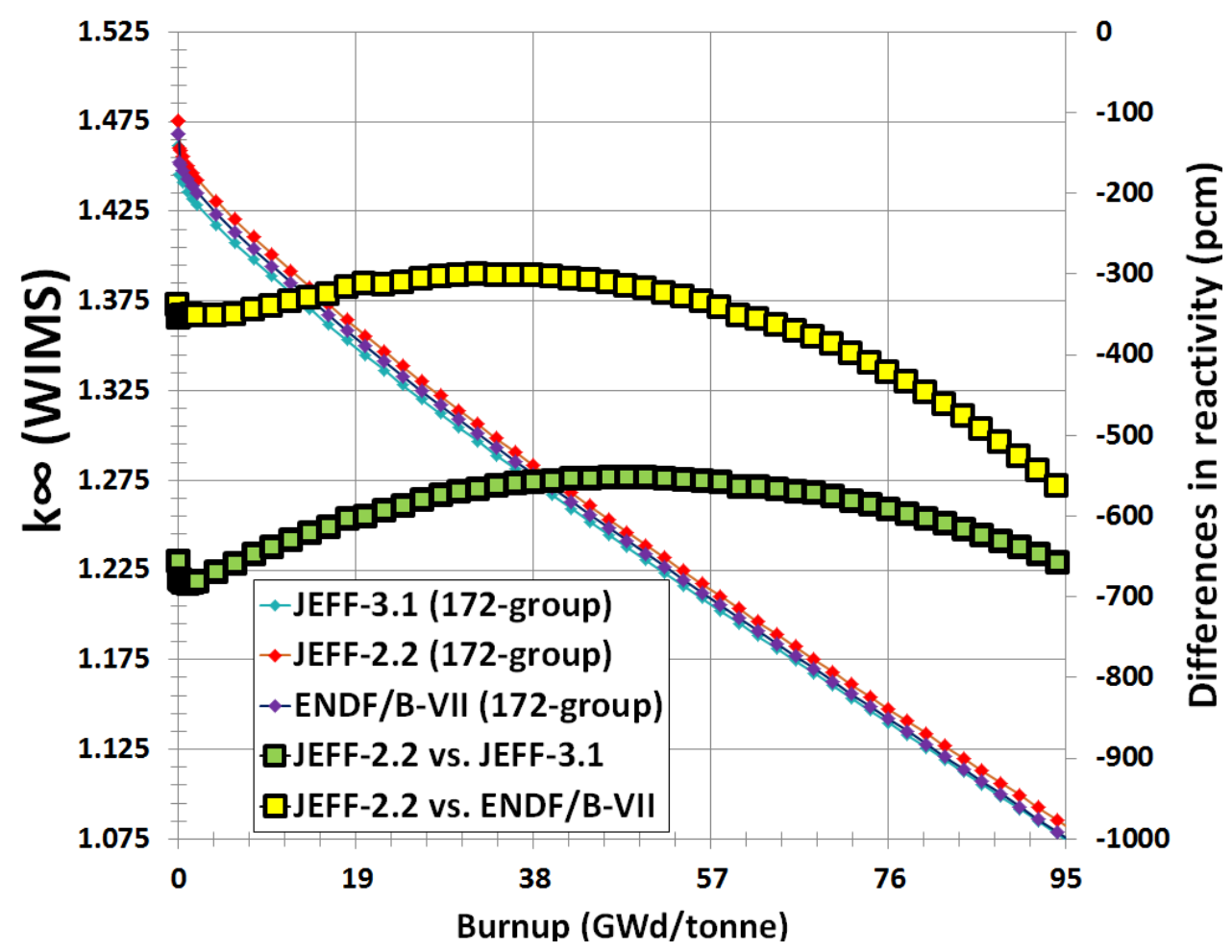

(b)

Fig. 8. Core depletion calculations with WIMS for three different data libraries (left) and the difference in reactivity with respect to JEF-2.2 (right) using candidate fuels: (a) $\mathrm{UO}_{2}$; (b) Duplex. 


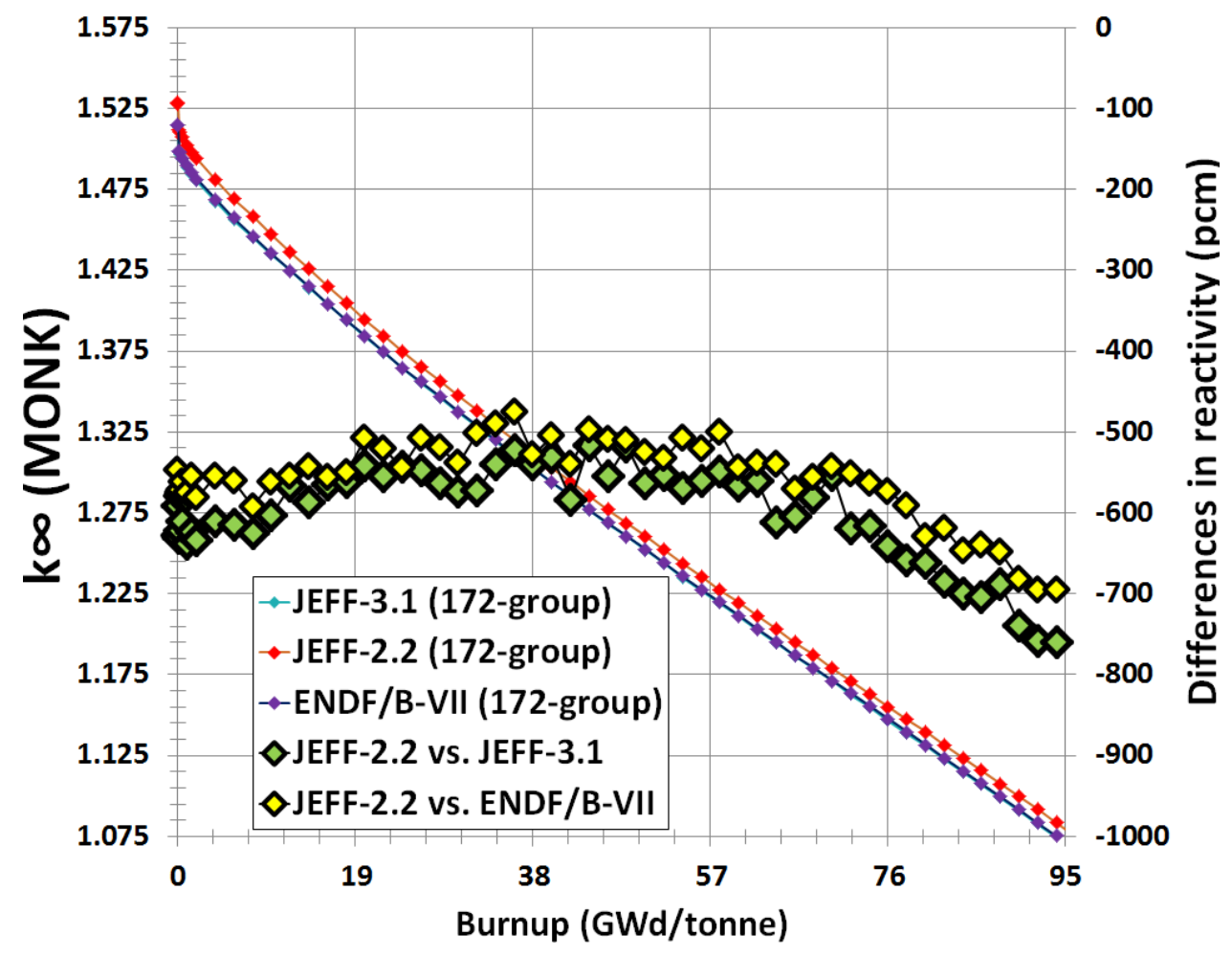

(a)

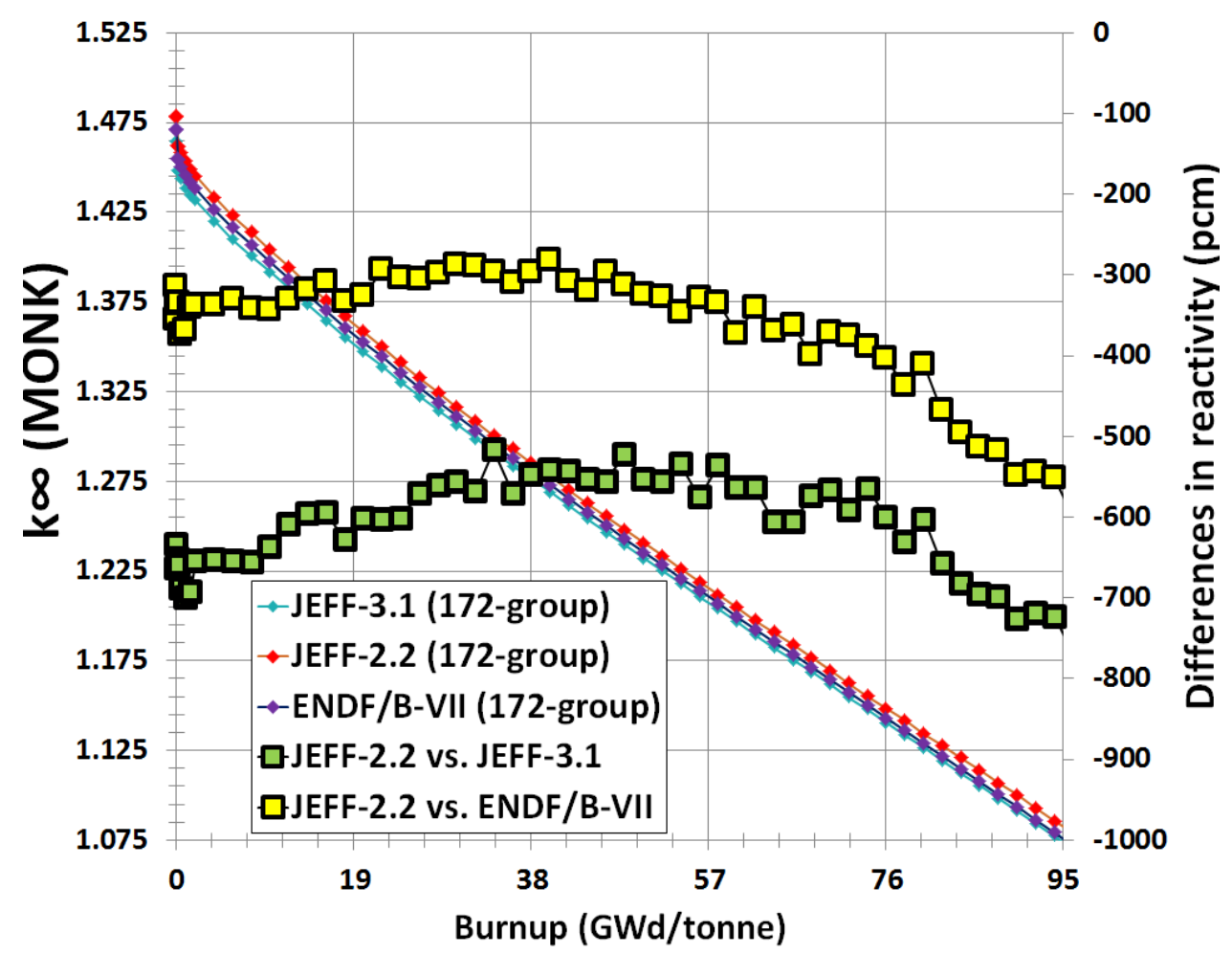

(b)

Fig. 9. Core depletion calculations with MONK for three different data libraries (left) and the difference in reactivity with respect to JEF-2.2 (right) using candidgate fuels: (a) $\mathrm{UO}_{2}$; (b) Duplex. 


\subsection{Assembly pin power}

Since the results between the codes exhibit an excellent agreement in terms of criticality benchmark calculations (as shown in Sect.3) and data library discrepancies (as shown in Sect.4) for the candidate fuels, only WIMS is considered for assembly pin power calculations in order to observe the data library discrepancies while using JEF-2.2, JEFF-3.1 and ENDF/B-VII libraries.

\begin{tabular}{|c|c|c|c|c|c|c|}
\hline & ENDF/ & 'B-VII & & & & 1.0209 \\
\hline & JEF- & 2.2 & & & & 1.0191 \\
\hline & JEFF- & 3.1 & & & & 1.019 \\
\hline$\%$ diff be & ween av & erage an & JEF-2.2 & & & 0.055605 \\
\hline & & & & & 1.0012 & 0.9912 \\
\hline & & & & & 1.0014 & 0.9918 \\
\hline & & & & & 1.0013 & 0.9918 \\
\hline & & & & & -0.00999 & -0.02017 \\
\hline & & & & 0.9695 & 0.9581 & 0.966 \\
\hline & & & & 0.973 & 0.9625 & 0.9691 \\
\hline & & & & 0.973 & 0.9625 & 0.9691 \\
\hline & & & & -0.1199 & -0.15238 & -0.10663 \\
\hline & & & 1.0006 & 0.9987 & 0.966 & 0.9613 \\
\hline & & & 1.0004 & 0.9992 & 0.9694 & 0.9648 \\
\hline & & & 1.0006 & 0.9991 & 0.9694 & 0.9648 \\
\hline & & & 0.013328 & -0.02002 & -0.11691 & -0.12092 \\
\hline & & 0.9695 & 0.9987 & & 0.9879 & 0.9608 \\
\hline & & 0.973 & 0.9992 & & 0.9894 & 0.9646 \\
\hline & & 0.973 & 0.9991 & & 0.9893 & 0.9645 \\
\hline & & -0.1199 & -0.02002 & & -0.0539 & -0.13477 \\
\hline & 1.0012 & 0.9695 & 0.9987 & & 0.9879 & 0.9608 \\
\hline & 1.0014 & 0.9625 & 0.9694 & 0.9894 & 0.9676 & 0.9645 \\
\hline & 1.0013 & 0.9625 & 0.9694 & 0.9893 & 0.9675 & 0.9644 \\
\hline & -0.00999 & 0.242424 & 1.007496 & -0.00505 & 0.69588 & -0.13133 \\
\hline 1.0209 & 0.9912 & 0.9581 & 0.966 & 0.9879 & 0.9643 & 0.9611 \\
\hline 1.0191 & 0.9918 & 0.9691 & 0.9648 & 0.9646 & 0.9645 & 0.9742 \\
\hline 1.019 & 0.9918 & 0.9691 & 0.9648 & 0.9645 & 0.9644 & 0.974 \\
\hline 0.055605 & -0.02017 & -0.37836 & 0.041459 & 0.801714 & -0.01037 & -0.45507 \\
\hline
\end{tabular}

Fig. 10. Pin power distribution of one octant assembly for $\mathrm{UO}_{2}$ fuel at $0 \mathrm{GWD} / \mathrm{T}$ using WIMS.

Assembly pin power calculations are performed with WIMS 172 energy group with the three candidate data libraries to investigate the data library discrepancies at BOL and EOL. It is observed in Figs. 10, 11, 12 and 13 that the relative differences in the assembly pin powers between the JEF-2.2 and average pin powers of the data libraries are almost always within $\sim 1 \%$. 


\begin{tabular}{|c|c|c|c|c|c|c|}
\hline & ENDF & /B-VII & & & & 1.0196 \\
\hline & JEF & 2.2 & & & & 1.0196 \\
\hline & JEFF & 3.1 & & & & 1.0195 \\
\hline$\%$ diff be & ween av & erage an & d JEF-2.2 & & & -0.00327 \\
\hline & & & & & 1.0001 & 0.9905 \\
\hline & & & & & 1.0001 & 0.9905 \\
\hline & & & & & 0.9997 & 0.9904 \\
\hline & & & & & -0.01333 & -0.00337 \\
\hline & & & & 0.9711 & 0.9588 & 0.9655 \\
\hline & & & & 0.9711 & 0.9588 & 0.9655 \\
\hline & & & & 0.9706 & 0.9579 & 0.9648 \\
\hline & & & & -0.01716 & -0.03129 & -0.02417 \\
\hline & & & 1.0003 & 0.9972 & 0.9653 & 0.9603 \\
\hline & & & 1.0003 & 0.9972 & 0.9653 & 0.9603 \\
\hline & & & 1.0005 & 0.9967 & 0.9644 & 0.9594 \\
\hline & & & 0.006665 & -0.01671 & -0.03108 & -0.03124 \\
\hline & & 0.9711 & 0.9972 & & 0.9857 & 0.9601 \\
\hline & & 0.9711 & 0.9972 & & 0.9857 & 0.9601 \\
\hline & & 0.9706 & 0.9967 & & 0.9848 & 0.959 \\
\hline & & -0.01716 & -0.01671 & & -0.03044 & -0.03819 \\
\hline & 1.0001 & 0.9711 & 0.9972 & & 0.9857 & 0.9601 \\
\hline & 1.0001 & 0.9588 & 0.9653 & 0.9857 & 0.963 & 0.96 \\
\hline & 0.9997 & 0.9579 & 0.9644 & 0.9848 & 0.9621 & 0.9591 \\
\hline & -0.01333 & 0.396329 & 1.070479 & -0.04565 & 0.754586 & -0.02778 \\
\hline 1.0196 & 0.9905 & 0.9588 & 0.9653 & 0.9857 & 0.963 & 0.96 \\
\hline 1.0196 & 0.9905 & 0.9655 & 0.9603 & 0.9601 & 0.96 & 0.9706 \\
\hline 1.0195 & 0.9904 & 0.9648 & 0.9594 & 0.959 & 0.9591 & 0.9699 \\
\hline-0.00327 & -0.00337 & -0.25548 & 0.142317 & 0.850606 & 0.072917 & -0.38808 \\
\hline
\end{tabular}

Fig. 11. Pin power distribution of one octant assembly for $\mathrm{UO}_{2}$ fuel at $100 \mathrm{GWD} / \mathrm{T}$ using WIMS. 


\begin{tabular}{|c|c|c|c|c|c|c|}
\hline & ENDF/ & |B-VII & & & & 1.0177 \\
\hline & JEF- & 2.2 & & & & 1.018 \\
\hline & JEFF- & 3.1 & & & & 1.0178 \\
\hline$\%$ diff be & tween av & erage an & d JEF-2.2 & & & -0.01637 \\
\hline & & & & & 1.0006 & 0.9917 \\
\hline & & & & & 1.0007 & 0.9916 \\
\hline & & & & & 1.0006 & 0.9916 \\
\hline & & & & & -0.00666 & 0.003362 \\
\hline & & & & 0.9737 & 0.963 & 0.9693 \\
\hline & & & & 0.9736 & 0.9629 & 0.9692 \\
\hline & & & & 0.9736 & 0.9629 & 0.9692 \\
\hline & & & & 0.003424 & 0.003462 & 0.003439 \\
\hline & & & 1.0006 & 0.9985 & 0.9697 & 0.9651 \\
\hline & & & 1.0004 & 0.9986 & 0.9696 & 0.965 \\
\hline & & & 1.0005 & 0.9986 & 0.9696 & 0.9653 \\
\hline & & & 0.009996 & -0.00334 & 0.003438 & 0.013817 \\
\hline & & 0.9737 & 0.9985 & & 0.9885 & 0.9647 \\
\hline & & 0.9736 & 0.9986 & & 0.9887 & 0.9645 \\
\hline & & 0.9736 & 0.9986 & & 0.9886 & 0.9645 \\
\hline & & 0.003424 & -0.00334 & & -0.01011 & 0.006912 \\
\hline & 1.0006 & 0.9737 & 0.9985 & 0.9885 & 0.9885 & 0.9647 \\
\hline & 1.0007 & 0.9629 & 0.9696 & 0.9887 & 0.9668 & 0.9644 \\
\hline & 1.0006 & 0.9629 & 0.9696 & 0.9886 & 0.9669 & 0.9644 \\
\hline & -0.00666 & 0.373871 & 0.993537 & -0.01011 & 0.75162 & 0.010369 \\
\hline 1.0177 & 0.9917 & 0.963 & 0.9697 & 0.9885 & 0.9669 & 0.9645 \\
\hline 1.018 & 0.9916 & 0.9692 & 0.965 & 0.9645 & 0.9644 & 0.9738 \\
\hline 1.0178 & 0.9916 & 0.9692 & 0.965 & 0.9645 & 0.9644 & 0.9738 \\
\hline-0.01637 & 0.003362 & -0.21323 & 0.162349 & 0.829445 & 0.08641 & -0.31834 \\
\hline
\end{tabular}

Fig. 12. Pin power distribution of one octant assembly for duplex fuel at $0 \mathrm{GWD} / \mathrm{T}$ using WIMS. 


\begin{tabular}{|c|c|c|c|c|c|c|}
\hline & ENDF & /B-VII & & & & 1.016 \\
\hline & JEF & -2.2 & & & & 1.0165 \\
\hline & JEFF & -3.1 & & & & 1.0162 \\
\hline$\%$ diff be & tween av & erage an & d JEF-2.2 & & & -0.02623 \\
\hline & & & & & 0.9995 & 0.9907 \\
\hline & & & & & 0.9997 & 0.9906 \\
\hline & & & & & 0.9996 & 0.9907 \\
\hline & & & & & -0.01 & 0.00673 \\
\hline & & & & 0.9753 & 0.9633 & 0.9682 \\
\hline & & & & 0.9751 & 0.963 & 0.9679 \\
\hline & & & & 0.9752 & 0.9631 & 0.968 \\
\hline & & & & 0.010255 & 0.013846 & 0.013776 \\
\hline & & & 1.0009 & 0.9968 & 0.9684 & 0.9632 \\
\hline & & & 1.0008 & 0.997 & 0.9682 & 0.9629 \\
\hline & & & 1.0009 & 0.9969 & 0.9682 & 0.963 \\
\hline & & & 0.006661 & -0.01003 & 0.006886 & 0.013847 \\
\hline & & 0.9753 & 0.9968 & & 0.9853 & 0.9626 \\
\hline & & 0.9751 & 0.997 & & 0.9856 & 0.9624 \\
\hline & & 0.9752 & 0.9969 & & 0.9854 & 0.9625 \\
\hline & & 0.010255 & -0.01003 & & -0.01691 & 0.010391 \\
\hline & 0.9995 & 0.9753 & 0.9968 & 0.9853 & 0.9853 & 0.9626 \\
\hline & 0.9997 & 0.963 & 0.9682 & 0.9856 & 0.965 & 0.962 \\
\hline & 0.9996 & 0.9631 & 0.9682 & 0.9854 & 0.965 & 0.962 \\
\hline & -0.01 & 0.429214 & 0.984645 & -0.01691 & 0.701209 & 0.02079 \\
\hline 1.016 & 0.9907 & 0.9633 & 0.9684 & 0.9853 & 0.9651 & 0.9621 \\
\hline 1.0165 & 0.9906 & 0.9679 & 0.9629 & 0.9624 & 0.962 & 0.9707 \\
\hline 1.0162 & 0.9907 & 0.968 & 0.963 & 0.9625 & 0.962 & 0.9707 \\
\hline-0.02623 & 0.00673 & -0.15497 & 0.193859 & 0.79662 & 0.107415 & -0.29532 \\
\hline
\end{tabular}

Fig. 13. Pin power distribution of one octant assembly for duplex fuel at $100 \mathrm{GWD} / \mathrm{T}$ using WIMS. 


\section{Conclusions}

This study performed numerical benchmark calculations for a SBF and long-life SMR lattice in a $13 \times 13$ arrangement. Three computationally different types of reactor physics codes: deterministic transport code WIMS, Monte Carlo code Serpent and hybrid Monte Carlo code MONK are used in this study to perform criticality benchmarking calculations.

In addition, data library discrepancies are performed for three candidate nuclear data files from the local repository: ENDF/B-VII, JEF2.2 and JEF3.1 for evaluating criticality values (using WIMS and MONK) and assembly pin power was evaluated (using WIMS only). The key findings of this study are as follows:

- It has been observed from the reactivity calculations that fuel candidates exhibit an excellent agreement between WIMS and MONK for the candidate data libraries: JEF-2.2, JEFF-3.1 and ENDF/B-VII. Average differences (over burnup) in eigenvalues between the codes are $\sim 100 \mathrm{pcm}$, whereas individual burnup steps show the maximum differences.

- Somewhat higher differences are observed in eigenvalues over burnup while comparing the results between Serpent and ANSWERS codes (WIMS and MONK).

- In comparison to JEF-2.2, both WIMS and MONK exhibit overall higher discrepancies with JEFF-3.1 than ENDF/B-VII. This arises due to the fact that JEF-2.2 and JEFF3.1 consistently exhibit the maximum and minimum $k_{\infty}$ values, respectively among the data libraries.

- MONK introduces higher discrepancies in $k_{\infty}$ values between the data libraries than WIMS for the candidate fuels. This might be due to the statistical nature, as this introduces additional error due to the statistical uncertainties.

- ENDF/B-VII consistently exhibits lower discrepancies in $k_{\infty}$ values between data libraries at BOL, which gradually increases with burnup. In addition, JEFF-2.2 library tends to slightly underestimate the $k_{\infty}$ in comparison to ENDF/B-VII, but still agrees relatively well with an acceptable difference.

- In regard to the assembly pin power comparison, candidate data libraries agree with very small differences (within $\sim 1 \%$ ).

However, it is understood that caution needs to be taken when using the results at higher burnup as the reactivity difference gradually increases with burnup. These increased discrepancies between data libraries during burnup are expected as they may be a result the data library discrepancies.

Finally, it can be concluded from this study that a good agreement in the results between the codes provides enhanced confidence that the deterministic reactor physics code WIMS can be reliably used in modeling SMR and SBF core systems with micro-heterogeneous 
$\mathrm{ThO}_{2}-\mathrm{UO}_{2}$ duplex fuel, offering the advantage of less expensive computation than that of the two other candidate codes: Monte Carlo code Serpent and hybrid Monte Carlo code MONK.

Future work will report the uncertainty analysis of the proposed SMR core. Since no experimental data is available for proposed new reactor designs, uncertainty quantification will be used as a validation tool. For uncertainty analysis, several sources of uncertainties (i.e. nuclear data and system parameters) will be considered to provide critically observables in terms of error bounds. Uncertainty propagation will provide more crucial information about codes benchmarking and their validity. These analyses will be reported in future work.

\section{References}

Alam, S.B., 2018. The Design of Reactor Cores for Civil Nuclear Marine Propulsion. Ph.D. thesis. University of Cambridge. Cambridge, UK.

Alam, S.B., Goodwin, C.S., Parks, G.T., 2019a. Assembly-level analyses of accident-tolerant cladding concepts for a long-life civil marine SMR core using micro-heterogeneous duplex fuel. Prog Nucl Energ 111, 24-41.

Alam, S.B., Goodwin, C.S., Parks, G.T., 2019b. Parametric neutronics analyses of lattice geometry and coolant candidates for a soluble-boron-free civil marine SMR core using micro-heterogeneous duplex fuel. Annals of Nuclear Energy 129, 1-12.

Alam, S.B., Kumar, D., Almutairi, B., Bhowmik, P.K., Goodwin, C., Parks, G.T., 2019c. Small modular reactor core design for civil marine propulsion using micro-heterogeneous duplex fuel. Part I: Assembly-level analysis. Nucl Eng Des. 346, 157-175.

Alam, S.B., Lindley, B.A., Parks, G.T., 2016a. Neutronic performance of high power density marine propulsion cores using $\mathrm{UO}_{2}$ and microheterogeneous $\mathrm{ThO}_{2}-\mathrm{UO}_{2}$ duplex fuels, in: Proc. PHYSOR 2016, Sun Valley, Idaho, USA. pp. 3519-3531.

Alam, S.B., Parks, G.T., Almutairi, B., Goodwin, C.S., 2018a. Neutronic assessment of accident-tolerant cladding concepts for civil nuclear marine propulsion cores. Part I: Reactivity \& spectral hardening, in: Proc. PHYSOR 2018, Cancun, Mexico. pp. 3142-3153.

Alam, S.B., Parks, G.T., Almutairi, B., Goodwin, C.S., 2018b. Neutronic assessment of accident-tolerant cladding concepts for civil nuclear marine propulsion cores. Part II: Rim effect \& reactivity feedback analysis, in: Proc. PHYSOR 2018, Cancun, Mexico. pp. 3154-3165.

Alam, S.B., Parks, G.T., Lindley, B.A., 2016b. Hot assembly and whole-core thermal-hydraulic analysis of a high power density marine core with neutronic/thermal-hydraulic coupling, in: Proc. PHYSOR 2016, Sun Valley, Idaho, USA. pp. 3506-3518.

Alam, S.B., Ridwan, T., Kumar, D., Almutairi, B., Bhowmik, P.K., Goodwin, C., Parks, G.T., 2019d. Small modular reactor core design for civil marine propulsion using micro-heterogeneous duplex fuel. Part II: Whole-core analysis. Nucl Eng Des. 346, 176-191.

Alam, S.B., Ridwan, T., Parks, G.T., Almutairi, B., Goodwin, C.S., 2018c. High power density reactor core design for civil nuclear marine propulsion. Part I: Assembly-level analysis, in: Proc. PHYSOR 2018, Cancun, Mexico. pp. 46-57.

Alam, S.B., Ridwan, T., Parks, G.T., Almutairi, B., Goodwin, C.S., 2018d. High power density reactor core design for civil nuclear marine propulsion. Part II: Whole-core analysis, in: Proc. PHYSOR 2018, Cancun, Mexico. pp. 58-69.

Clegg, R., Shanawany, M.E., 2012. Examples of SMR designs. Ingenia 52, 46-50.

Cooper, M., 2014. Small modular reactors and the future of nuclear power in the united states. Energy Research \& Social Science 3, 161-177.

Fan, H., 2012. The Conceptual Design of a Marine Propulsion Reactor Core. Master's thesis. Department of Engineering, University of Cambridge. Cambridge, UK.

Fratoni, M., Terrani, K.A., 2017. Pwr core design with metal matrix micro-encapsulated (M3) fuel. Progress in Nuclear Energy 100, 419-426. 
Galperin, A., Shwageraus, E., Todosow, M., 2002. Assessment of homogeneous thorium/uranium fuel for Pressurized Water Reactors. Nucl. Technol. 138, 111-122.

Hirdaris, S., Cheng, Y., Shallcross, P., Bonafoux, J., Carlson, D., Prince, B., Sarris, G., 2014a. Considerations on the potential use of nuclear small modular reactor (SMR) technology for merchant marine propulsion. Ocean Eng. 79, 101-130.

Hirdaris, S., Cheng, Y., Shallcross, P., Bonafoux, J., Carlson, D., Sarris, G., 2014b. Concept design for a suezmax tanker powered by a $70 \mathrm{MW}$ small modular reactor. Transactions of the Royal Institution of Naval Architects Part A: International Journal of Maritime Engineering 156, 37-59.

Hutton, L., Smith, N., 2001. Use of a hybrid Monte Carlo technique for power shape calculations. Springer.

IAEA, 2014. Advances in small modular reactor technology developments.

Leppänen, J., 2010. Performance of woodcock delta-tracking in lattice physics applications using the serpent monte carlo reactor physics burnup calculation code. Annals of Nuclear Energy 37, 715-722.

Leppänen, J., 2012. Serpent-a continuous-energy monte carlo reactor physics burnup calculation code. VTT Technical Research Centre of Finland .

Leppänen, J., Isotalo, A., 2012. Burnup calculation methodology in the serpent 2 Monte Carlo Code. Technical Report. American Nuclear Society, Inc., 555 N. Kensington Avenue, La Grange Park, Illinois 60526 (United States).

Leppänen, J., Pusa, M., 2009. Burnup calculation capability in the PSG2/Serpent Monte Carlo reactor physics code, in: Proc. Int. Conf. Advances in Mathematics, Computational Methods, and Reactor Physics, Saratoga Springs, NY.

Leppänen, J., Pusa, M., Viitanen, T., Valtavirta, V., Kaltiaisenaho, T., 2014. The serpent monte carlo code: Status, development and applications in 2013, in: SNA+ MC 2013-Joint International Conference on Supercomputing in Nuclear Applications+ Monte Carlo, EDP Sciences. p. 06021.

Lindley, B., Hosking, J., Smith, P., Powney, D., Tollit, B., Newton, T., Perry, R., Ware, T., Smith, P., 2017. Current status of the reactor physics code WIMS and recent developments. Annals of Nuclear Energy 102, $148-157$.

Lokhov, A., Sozoniuk, V., Rothwell, G., Cometto, M., Paillere, H., Crozat, M., Joon, K., McGough, M., Ingersoll, D., Rickman, R., et al., 2016. Small modular reactors: Nuclear energy market potential for near-term deployment. Technical Report. Organisation for Economic Co-Operation and Development.

Long, D., Richards, S., Smith, P., Baker, C., Bird, A., Davies, N., Dobson, G., Fry, T., Hanlon, D., Perry, R., Shepherd, M., 2015. MONK10: A Monte Carlo code for criticality analysis, in: Proc. Int. Conf. Nuclear Criticality Safety (ICNC 2015), Charlotte, NC. pp. 923-935.

MacDonald, P., Lee, C., 2004. Use of thoria-urania fuels in PWRs: A general review of a NERI project to assess feasible core designs, economics, fabrication methods, in-pile thermal/mechanical behavior, and waste form characteristics. Nucl. Technol. 147, 1-7.

Newton, T., 2009a. 'Monte Carlo Modules-MONK' inside WIMS: A Modular Scheme for Neutronic Calculations-User Guide for Version 10. ANSWERS/WIMS(08)9, The ANSWERS Software Service.

Newton, T., 2009b. WIMS: A Modular Scheme for Neutronic Calculations-User Guide for Version 10. ANSWERS/WIMS(08)9, The ANSWERS Software Service.

Newton, T., Hosking, G., Hutton, L., Powney, D., Turland, B., Shuttleworth, E., 2008. Developments within WIMS10, in: Proc. PHYSOR 2008, Interlaken, Switzerland.

Otto, R.T., 2013. Core Optimization in a Thorium-based Civil Marine Propulsion Reactor. Master's thesis. Department of Engineering, University of Cambridge.

Pramuditya, S., Takahashi, M., 2013. Core design study for power uprating of integral primary system PWR. Annals of Nuclear Energy 59, 16-24.

Ramana, M., Hopkins, L.B., Glaser, A., 2013. Licensing small modular reactors. Energy 61, 555-564.

Sun, H., 2014. Marine Reactor Core Physics Study. Master's thesis. Department of Engineering, University of Cambridge. Cambridge, UK.

Todosow, M., Galperin, A., Herring, S., Kazimi, M., Downar, T., Morozov, A., 2005. Use of thorium in light water reactors. Nucl. Technol. 151, 168-176.

Vujić, J., Antić, D.P., Vukmirović, Z., 2012a. Environmental impact and cost analysis of coal versus nuclear 
power: the us case. Energy 45, 31-42.

Vujić, J., Bergmann, R.M., Škoda, R., Miletić, M., 2012b. Small modular reactors: Simpler, safer, cheaper? Energy 45, 288-295.

Zainuddin, N.Z., 2015. In-core Optimisation of Thorium-Plutonium-fuelled PWR Cores. Ph.D. thesis. University of Cambridge.

Zhang, J., 2013. Commercial Nuclear Marine Reactor Physics Design for Uranium Fuel. Master's thesis. Department of Engineering, University of Cambridge. Cambridge, UK.

Zhao, X., 2001. Micro-heterogeneous Thorium Based Fuel Concepts for Pressurized Water Reactors. Ph.D. thesis. Massachusetts Institute of Technology. Cambridge, MA.

Zohuri, B., McDaniel, P., 2019. Advanced Smaller Modular Reactors: An Innovative Approach to Nuclear Power. Springer. 